Article

\title{
Energy Retrofit Strategies for Residential Building Envelopes: An Italian Case Study of an Early-50s Building
}

\author{
Luca Evangelisti, Claudia Guattari * and Paola Gori \\ Department of Engineering, University of Roma TRE, via Vito Volterra 62, Rome 00146, Italy; \\ E-Mails: luca.evangelisti@uniroma3.it (L.E.); paola.gori@uniroma3.it (P.G.) \\ * Author to whom correspondence should be addressed; E-Mail: claudia.guattari@uniroma3.it; \\ Tel.: +39-06-5733-3289.
}

Academic Editors: Francesco Asdrubali and Pietro Buzzini

Received: 13 June 2015 / Accepted: 30 July 2015 / Published: 5 August 2015

\begin{abstract}
During the last few years, the issues of energy efficiency and energy saving have dominated the buildings research field. New constructions are based on efficient design and, because of this, the real challenge is to retrofit existing buildings. Italian standards impose thermal transmittance limits for opaque and transparent surfaces, according to the climatic area. In order to understand buildings' energy behavior, an accurate analysis, carried out by employing advanced calculation codes and instrumental diagnosis - provided by the use of heat flow meter, surface temperature probes and thermal imaging camera - is needed. In this paper, a structure built in the $50 \mathrm{~s}$ has been analyzed, by means of a measurement campaign, to investigate the building's characteristics and its vulnerability. Finally, some retrofit hypotheses have been evaluated by means of a well-known dynamic code. All investments have to be analyzed under a financial point of view, considering materials and installation costs. For this reason, the payback time has been calculated in order to understand how quickly the energy upgrading can be repaid.
\end{abstract}

Keywords: buildings energy analysis; existing building retrofit; dynamic building simulation

\section{Introduction}

New buildings are based on efficient design and, because of this, in order to obtain an energy saving in the building sector, the real challenge is to retrofit existing constructions. Technical solutions have been characterized by an evolution over the years. For this reason, it is important to understand buildings 
energy behavior through accurate energy analysis [1-4]. Moreover, today it is possible to employ many software tools, based on advanced calculation codes, and perform instrumental diagnosis. It is well known that the building's component performances are important to define the annual energy consumption [5-13]. Wall performance depends on its thermal resistance, which is a measure of how well an envelope resists the heat-flow, and on the material heat capacity, which describes its thermal storage capability. Higher thermal resistance values allow us to obtain a better insulation and depend on thermal conductivity and thickness of each layer. In some conditions, the actual thermal resistance of building envelope components might not always agree with the value estimated during the design phase. Therefore, it is important to analyze the building envelope through in situ measurements by means of a non-destructive method that requires the use of a heat flow meter and a measurement time of at least $72 \mathrm{~h}$ [14]. It is important to remember that thermal transmittance measurements could be wrong if structural abnormalities are found in the measuring points. For this reason, a preliminary thermographic analysis is required to assess the correct application of the sensors, as shown, e.g., by Asdrubali et al. [15] that presented the results of a thermal transmittance measurement campaign performed for several building types. Moreover, the thermal imaging camera is very important to investigate the building's characteristics and its vulnerability. In their study, De Lieto Vollaro et al. [16] used a thermal imaging camera to analyze the envelope of an old building, detecting some badly-covered holes. The instrumental diagnosis is an important step to investigate the building's envelope and recreate a model able to represent the real structure behavior.

Moreover, the choice of an appropriate calculation code is important during the energy analysis [17]: building energy demands values obtained by means of semi-stationary software and dynamic ones can provide different results. For this reason, in their studies, Evangelisti et al. [18] and De Lieto Vollaro et al. [19] compared two models in order to analyze the energy performance of different buildings, one of them based on a simplified approach and the other one based on a time-dependent method, concluding for the critical importance of employing accurate dynamic analysis tools.

In particular, this paper is related to the theme of the redevelopment of social housing built in the postwar period, which was already addressed in the mid-1980s in countries like France and Germany. This social housing was characterized by extensive government interventions for meeting the housing demand. The rapid physical deterioration of this heritage building led to government interventions aimed at architectural, structural and energetic upgrading.

This study deals with the theme of the redevelopment of social housing through the thermal behavior analysis of an early-1950s building, by means of an instrumental diagnosis, based on heat flow meter and thermal imaging camera measurements. Starting from these data, a calibrated building model has been created and dynamic simulations have been performed to evaluate the influence of different retrofit measures on the resulting annual energy demands. It is well known that all the investments have to be investigated under a financial point of view, by taking into account materials and installation costs. Because of this, the payback time has been evaluated in order to assess how quickly the energy upgrading can be repaid. 


\section{Methodology}

Buildings energy retrofit analysis requires simulation models able to reproduce the structure thermal behavior. It is well known that, in order to build these models, a dynamic software such as TRNSYS (Transient System Simulation Tool) [20] is needed. This software is based on an advanced calculation code, which applies the transfer function approach of Mitalas [21]. It has been widely demonstrated that, using this software, it is possible to properly reproduce the building geometry and the external environmental conditions. TRNSYS Build allows recreating the building model, and the external environmental conditions are applied by using TRNSYS Studio [22-24]. In this study, the weather conditions of the year 2014 have been reproduced through a TRNSYS Studio specific type, being the types small program codes written in FORTRAN or $\mathrm{C}++$. The dynamic software is able to provide the thermal loads for each hour during the day. Building's characteristics can be deduced by visual inspections and in situ measurements, through the use of heat flow meter, temperature probes and a thermal imaging camera. The heat flow meter allows estimating walls thermal transmittance, the temperature probes are employed to measure air temperature inside the construction and thermal imaging camera allows analyzing the building envelope, in order to assess heat losses. Instrumental measurements are important to obtain a calibrated model. The calibration process is based on two index calculations: the Mean Bias Error (MBE) and the Coefficient of Variation of the Root Mean Squared Error (CVRMSE) [25], defined as:

$$
\begin{gathered}
\operatorname{MBE}(\%)=\frac{\sum_{i=1}^{N p}\left(m_{i}-s_{i}\right)}{\sum_{i=1}^{N p}\left(m_{i}\right)} \\
C V_{\text {RMSE }}(\%)=\frac{\sqrt{\left(\sum_{i=1}^{N p}\left(m_{i}-s_{i}\right)^{2} / N p\right.}}{\bar{m}}
\end{gathered}
$$

where $m_{i}$ and $s_{i}$ are respectively measured and simulated data values for each model instance $i ; N_{p}$ is the number of data points at interval $p$ and $\bar{m}$ is the average of the measured data values. Currently, building energy simulation models are defined as calibrated if they meet the criteria set out by ASHRAE (American Society of Heating, Refrigerating and Air-Conditioning Engineers) Guideline 14 (MBE hourly criteria up to $10 \%$ and $\mathrm{CV}_{\mathrm{RMSE}}$ hourly criteria up to $30 \%$ ) [26]. After calibrating the model, it is possible to use it for the simulation of retrofit strategies, in order to improve the building's thermal performance and reduce annual energy needs. Figure 1 shows a scheme of the approach employed to address the retrofit design.

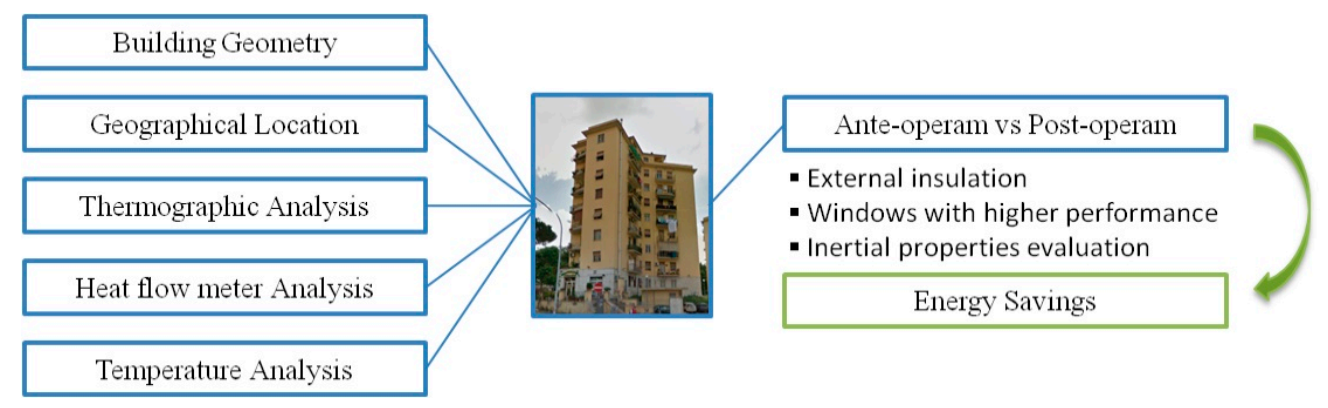

Figure 1. Schematic approach for the retrofit design. 
All investments have to be analyzed under a financial point of view, considering materials and installation costs. Just to exemplify such financial considerations, we focus here on the retrofit based on the addition of an external coating of expanded polystyrene and we calculate how quickly the energy upgrading will be repaid. The ratio between the starting investment and the annual savings due to the additional thermal insulation is defined as payback time (PBT) and can be expressed as follows:

$$
P B T=\frac{C_{i} \times R_{\text {ante }} \times R_{\text {post }} \times E}{C_{e} \times\left(R_{\text {post }}-R_{\text {ante }}\right) \times 24 \times H D D}
$$

where $C_{i}$ is the material installation cost, $R_{a n t e}$ is the thermal resistance before the retrofit, $R_{\text {post }}$ is the thermal resistance after the retrofit, $E$ is the heating system efficiency, $C_{e}$ is the energy cost and $D D$ are the climatic zone heating degree days [27].

\section{The Case Study}

\subsection{Building Characteristics}

The proposed case study is represented by a construction built in Rome during the 1950s, belonging to a neighborhood placed in a central area of the city characterized by ten identical buildings and sixteen structures built in the same period. Figures 2 and 3 show its particular geometry, characterized by a star shape. The building presents a stairwell located in the center of the structure with the residential units organized all around. Table 1 shows the main information about the building geometry and geographical position. The vertical walls are characterized by an external layer made of concrete and an internal layer made of hollow bricks. The walls are plastered on both sides. The building doesn't have any basement.

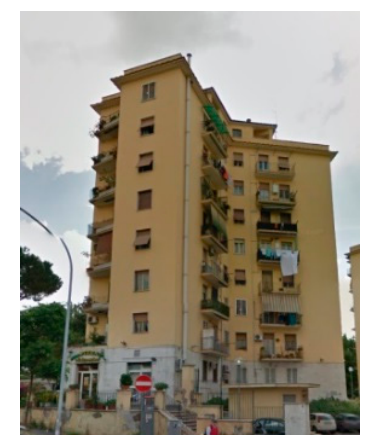

Figure 2. The case study.

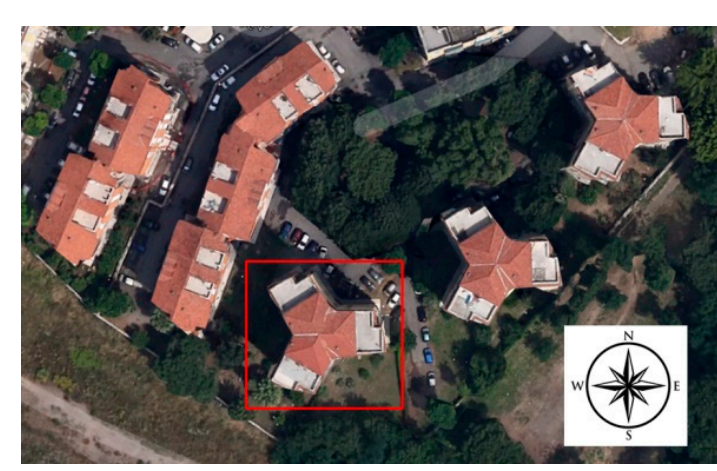

(a)

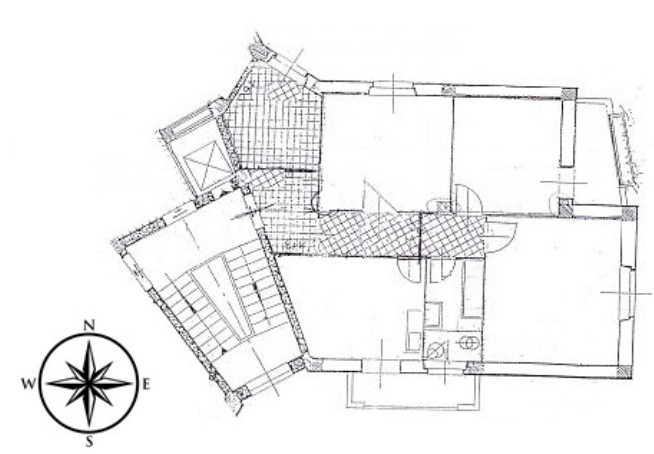

(b)

Figure 3. (a) The analyzed building and its orientation; (b) Residential unit plan. 
Table 1. Building characteristics and geographical position.

\begin{tabular}{cc}
\hline Building's characteristics & Values \\
\hline Building Volume $\left[\mathrm{m}^{3}\right]$ & 6984 \\
Building Total Surface $\left[\mathrm{m}^{2}\right]$ & 2948.4 \\
Surface-Volume ratio & 0.42 \\
Opaque Surface Area $\left[\mathrm{m}^{2}\right]$ & 2594.16 \\
Transparent Surface Area $\left[\mathrm{m}^{2}\right]$ & 354.24 \\
Residential Units & 24 \\
Climatic Zone & $\mathrm{D}$ \\
Latitude & $41^{\circ} 54^{\prime} 39^{\prime \prime} 24 \mathrm{~N}$ \\
Longitude & $12^{\circ} 28^{\prime} 54^{\prime \prime} 48 \mathrm{E}$ \\
\hline
\end{tabular}

Wall characteristics have been deduced by visual inspections of the bins containing the shutters, as shown in Figure 4. Despite this, assuming visual inspections not sufficient to understand the actual walls stratigraphy (and consequently not sufficient to estimate its thermal transmittance), in situ measurements of the wall thermal transmittance have been conducted by using a heat flow meter [28]. The instrument is provided with two temperature sensors: a plate that has to be applied on the inner side of the wall and an external wireless temperature probe. The heat flow meter proper operation requires the absence of thermal bridges. For this reason, a thermographic investigation has been carried out inside a residential unit (Figure 5).

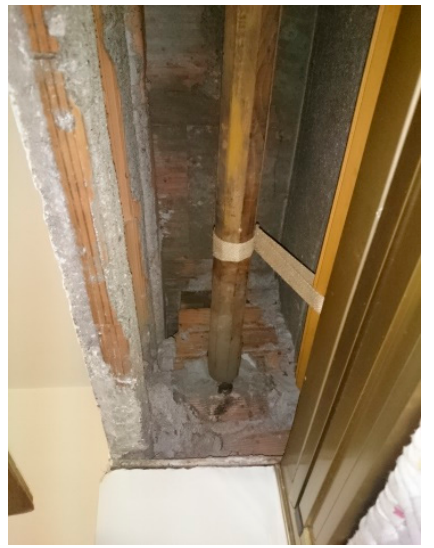

(a)

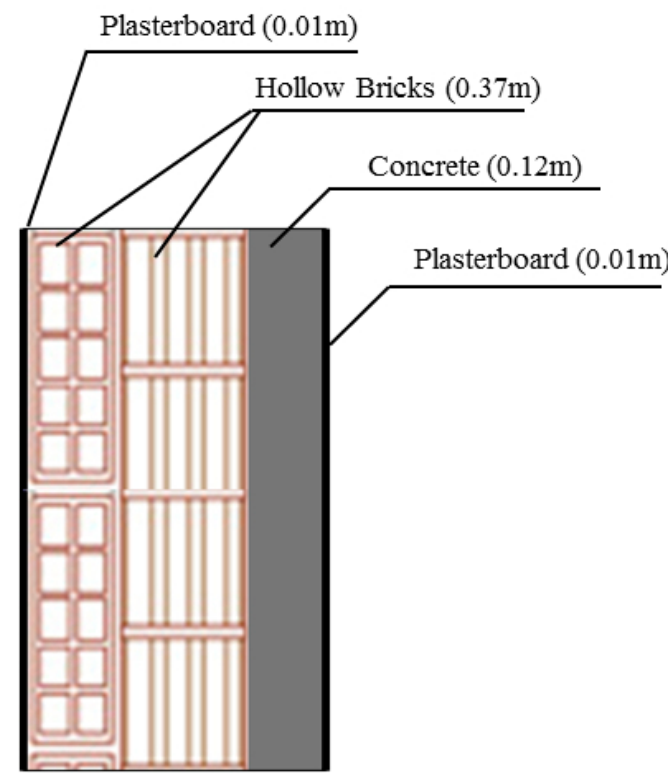

(b)

Figure 4. (a) Visual inspections of the bins containing the shutters; (b) Wall stratigraphy.

In agreement with to the Standard ISO 9869, measurement time has been chosen equal to 10 days (from 13 December until 23 December) according to the needs of some residents that have kindly allowed performing the measurement campaign in their apartments. The heat flow plate and the external temperature probes have been applied on a north-facing wall, in order to avoid the direct solar radiation. The measured thermal transmittance value is equal to $0.918 \mathrm{~W} / \mathrm{m}^{2} \mathrm{~K}$. As a result of the visual inspection 
and of the transmittance measurement, the walls, roof and windows main characteristics have been deduced and they are listed in Tables $2-4$.
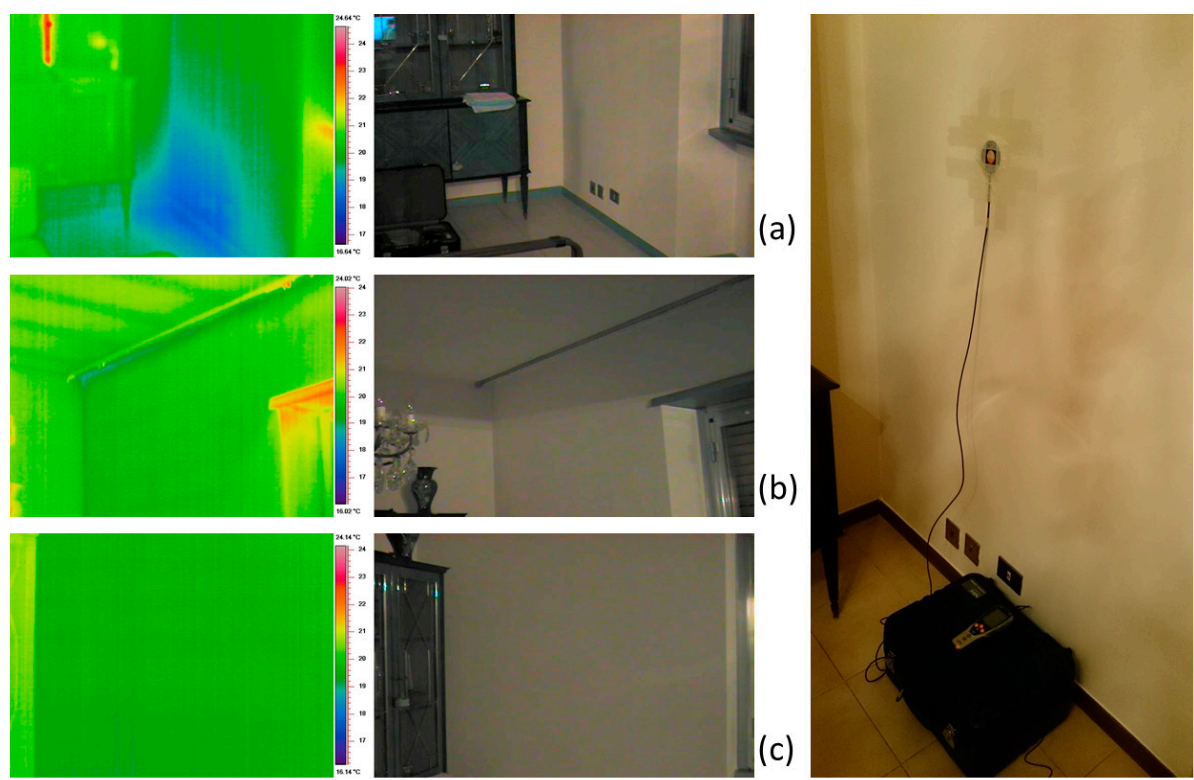

(d)

Figure 5. (a-c) Preliminary thermographic and visual investigation of the tested wall; (d) In situ heat flow meter measurements.

Table 2. Walls stratigraphy.

\begin{tabular}{|c|c|c|c|c|}
\hline & $\begin{array}{c}\text { Thermal Conductivity } \\
{[\mathrm{W} / \mathrm{mK}]}\end{array}$ & $\begin{array}{c}\text { Specific Heat } \\
\text { Capacity [J/kgK] }\end{array}$ & $\begin{array}{c}\text { Mass Density } \\
{\left[\mathrm{kg} / \mathrm{m}^{3}\right]}\end{array}$ & $\begin{array}{c}\text { Thickness } \\
{[\mathrm{m}]}\end{array}$ \\
\hline \multicolumn{5}{|l|}{ Internal side } \\
\hline Plasterboard & 0.350 & 840 & 1000 & 0.010 \\
\hline Hollow Bricks & 0.589 & 840 & 700 & 0.370 \\
\hline Concrete & 0.510 & 1000 & 1500 & 0.120 \\
\hline Plasterboard & 0.350 & 840 & 1000 & 0.010 \\
\hline \multicolumn{5}{|l|}{ External side } \\
\hline & & & Total Thickness & 0.51 \\
\hline & & & U-value & $0.918 \mathrm{~W} / \mathrm{m}^{2} \mathrm{~K}$ \\
\hline
\end{tabular}

Table 3. Roof stratigraphy.

\begin{tabular}{ccccc}
\hline & $\begin{array}{c}\text { Thermal } \\
\text { Conductivity [W/mK] }\end{array}$ & $\begin{array}{c}\text { Specific Heat } \\
\text { Capacity [J/kgK] }\end{array}$ & $\begin{array}{c}\text { Mass Density } \\
{\left[\mathbf{k g} / \mathbf{m}^{3}\right]}\end{array}$ & $\begin{array}{c}\text { Thickness } \\
{[\mathbf{m}]}\end{array}$ \\
\hline Internal side & & & & \\
Plasterboard & 0.350 & 840 & 1000 & 0.010 \\
Hollow Bricks & 0.589 & 840 & 700 & 0.240 \\
Cement Mortar & 1.250 & 1700 & 2000 & 0.050 \\
Waterproof Membrane & 0.220 & 840 & 343 & 0.005 \\
Cement Mortar & 1.250 & 1700 & 2000 & 0.050 \\
External side & & \multicolumn{3}{c}{ Total Thickness } \\
\hline & & $\mathbf{0 . 3 5 5}$ \\
\hline
\end{tabular}


Table 4. Windows characteristics.

\begin{tabular}{ccc}
\hline & Thermal Transmittance $\left[\mathbf{W} / \mathbf{m}^{2} \mathbf{K}\right]$ & g-value \\
\hline Frame & 2.27 & - \\
Single Glass 4 mm & 5.38 & 0.855 \\
\hline
\end{tabular}

Moreover, as it is shown in Figure 6, in order to locate the heat losses sources, a thermal imaging analysis has been carried out also for the building envelope. As it can be seen, the building bearing structure is quite clear indicating that building insulation is not very effective.
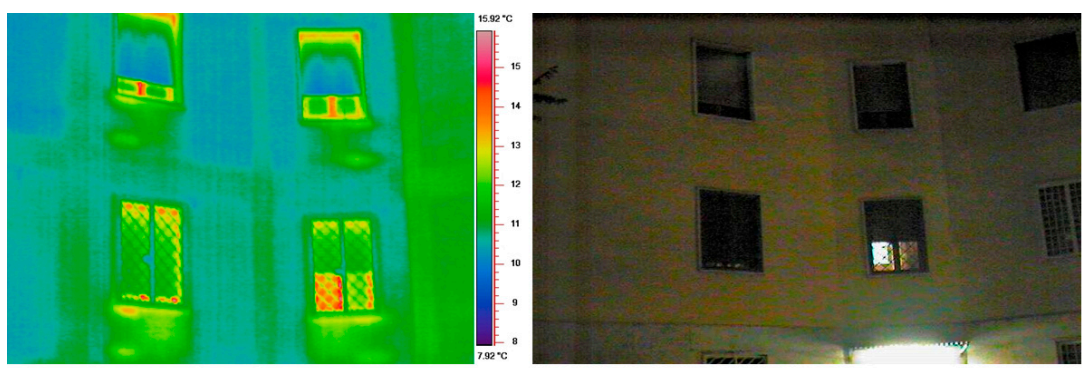

(a)
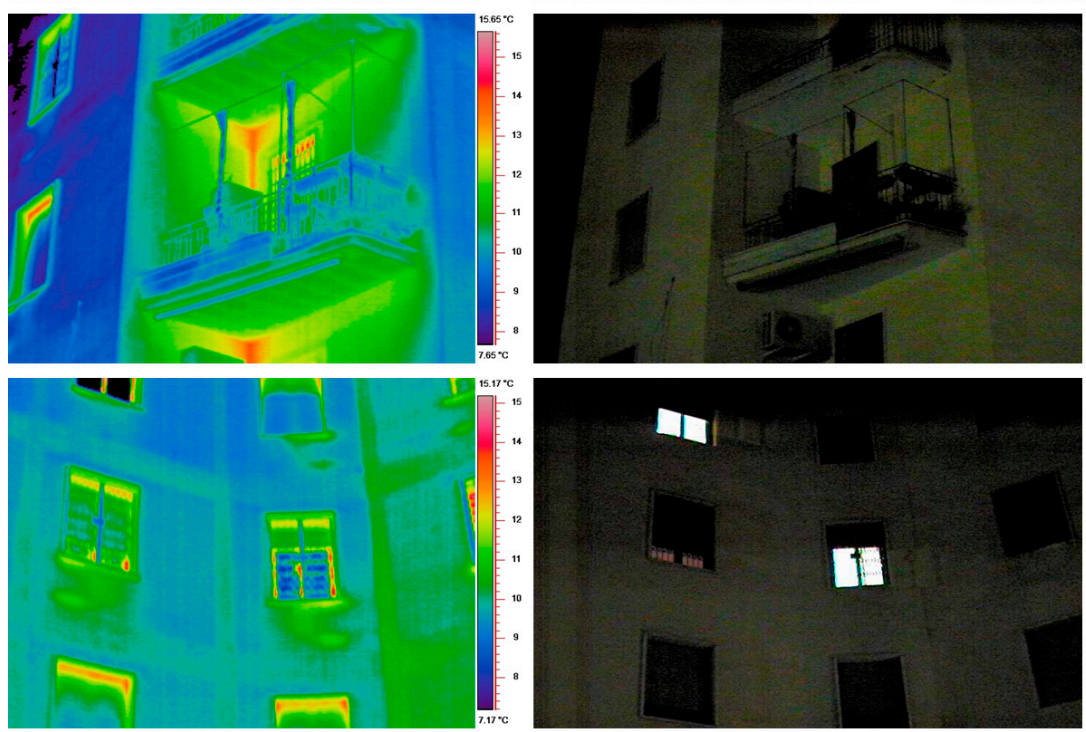

(b)

Figure 6. Thermographic (left) and gray-scale image (right) of the building envelope.

\subsection{Building Modeling}

The dynamic software TRNSYS has been used to create a model of the real building. In order to simulate the building energy demands, not having reliable information about the real plant, an ideal air conditioning system characterized by infinite power and different set-point temperatures was considered: the set-point temperatures are equal to $26^{\circ} \mathrm{C}$ for cooling and $20^{\circ} \mathrm{C}$ for heating [29]. The air conditioning system has been considered $24 \mathrm{~h}$ working. Taking into account some interviews conducted with some residents, an average number of two persons, always present, has been considered in the model. Moreover, ventilation rates have been set equal to $0.3 \mathrm{l} / \mathrm{h}$. Solar shading devices have not been modeled.

According to the measured thermal transmittance value (U-value equal to $0.918 \mathrm{~W} / \mathrm{m}^{2} \mathrm{~K}$ ) and to the visual inspections, the wall's stratigraphy has been built using the software. Moreover, the 2014 weather data for Rome have been collected (files acquired by the Roma TRE University weather station) 
and used as input and the model has been calibrated using the results of temperature measurements inside an apartment. Analyzing measured and simulated temperatures, the MBE and the CVRMSE have been calculated. The MBE takes a value equal to $4.8 \%$ and the CVRMSE is equal to $6 \%$.

Table 5 lists the dynamic thermal performance of vertical and horizontal opaque surfaces.

Table 5. Walls and roof dynamic thermal performance.

\begin{tabular}{lc}
\hline Walls & \\
\hline Surface mass & $439 \mathrm{~kg} / \mathrm{m}^{2}$ \\
Dynamic thermal transmittance & $0.157 \mathrm{~W} / \mathrm{m}^{2} \mathrm{~K}$ \\
Thermal attenuation & 0.172 \\
Thermal lag & $12.86 \mathrm{~h}$ \\
\hline Roof & \\
\hline Surface mass & $369.7 \mathrm{~kg} / \mathrm{m}^{2}$ \\
Dynamic thermal transmittance & $0.507 \mathrm{~W} / \mathrm{m}^{2} \mathrm{~K}$ \\
Thermal attenuation & 0.344 \\
Thermal lag & $9.29 \mathrm{~h}$ \\
\hline
\end{tabular}

The monitoring campaigns have been conducted throughout the season, acquiring data by means of different brief measurements $(48 \mathrm{~h})$, taking into account the person/apartment availability. Figure 7 shows the comparison between simulated and measured temperatures, considering only one of the several conducted measurement campaigns.

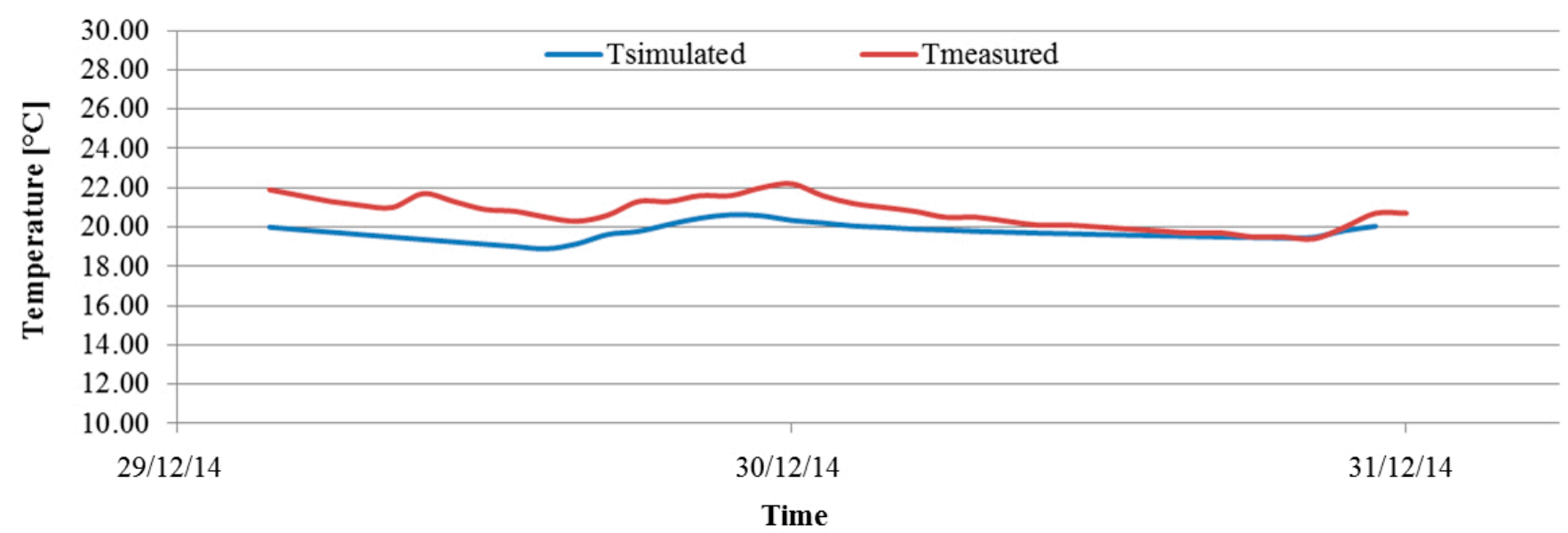

Figure 7. Comparison between simulated and measured temperatures.

Figure 8 shows the comparison between the modeled weather conditions for the 2014 and the TRNSYS weather-data. As shown, analyzing environmental temperatures during January and August supplied by the software and comparing them with the same months of the 2014, it is possible to observe that TRNSYS original weather-data are rather different during the winter, but they are very similar during the summer. This comparison has been done in order to verify the consistency between TRNSYS weather-data and the measured ones. The year 2014 was characterized by mild winter temperatures. Slightly different results could be obtained using TRNSYS weather-data, but the small discrepancy observed would not alter the overall conclusions of this work. 
Starting from the analysis of the original building (the so called "base case"), different retrofit strategies have been simulated in order to understand the building's thermal behavior.
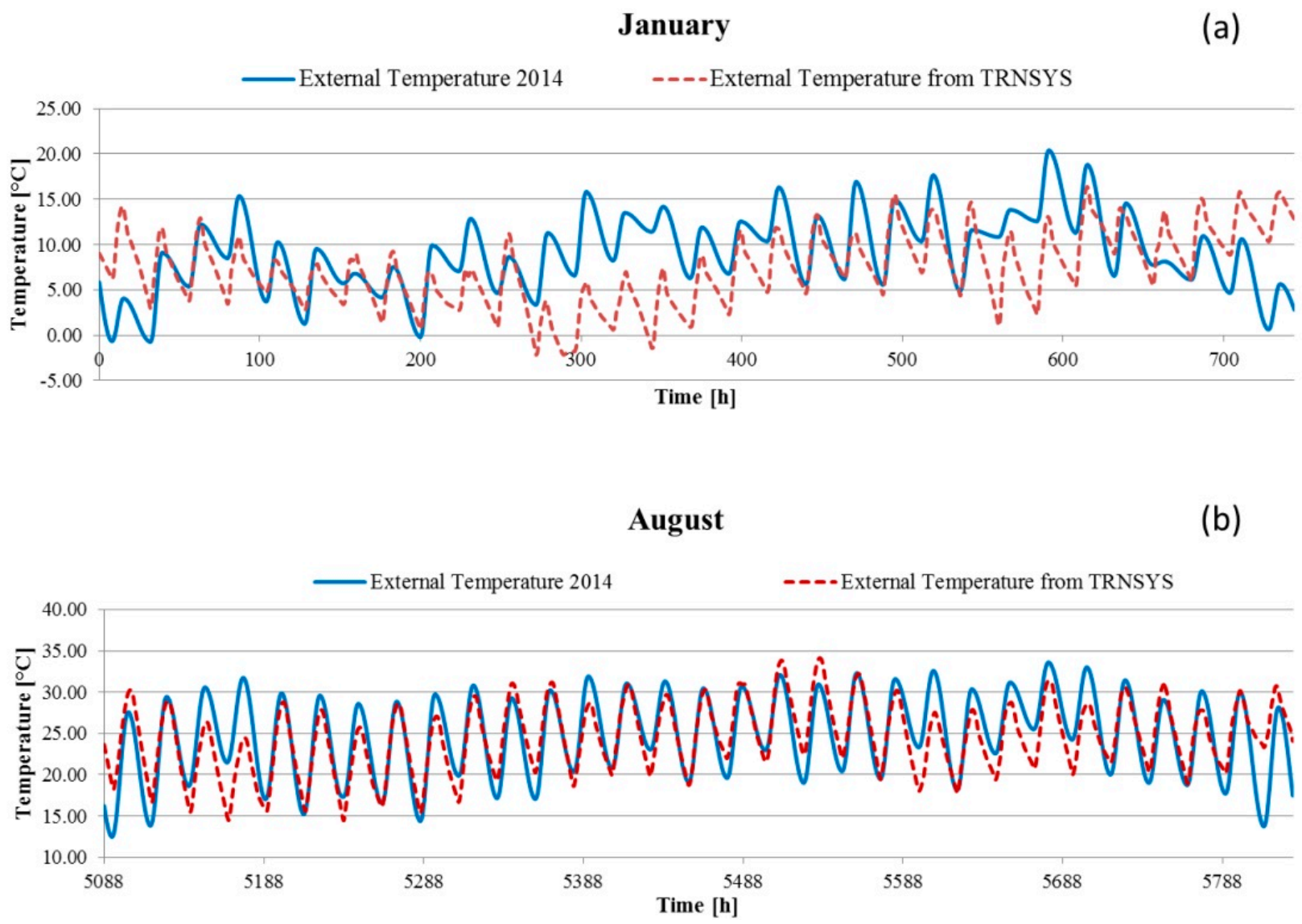

Figure 8. (a) Environmental temperatures in January; (b) Environmental temperatures in August.

\subsection{Retrofit Strategies}

In order to carry out the building envelope refurbishment, some possible interventions have been considered. Starting from the so-called "base case", three different types of windows have been tested, as can be seen in Table 6 .

Table 6. Windows tested through the model.

\begin{tabular}{ccccc}
\hline & $\begin{array}{c}\text { Structure } \\
{[\mathbf{m m}]}\end{array}$ & $\begin{array}{c}\text { Thermal } \\
\text { Transmittance } \\
{\left[\mathbf{W} / \mathbf{m}^{2} \mathbf{K}\right]}\end{array}$ & g-value & $\begin{array}{c}\text { Thermal } \\
\text { Transmittance Limit } \\
\text { (Climatic Zone D) }\end{array}$ \\
\hline Frame & - & 2.27 & - & - \\
Double Glaze-AIR & $4 / 16 / 4$ & 2.83 & 0.755 & $\times$ \\
Double Glaze-ARGON & $4 / 16 / 4$ & 1.40 & 0.589 & $\sqrt{ }$ \\
Double Glaze-AIR (Low g) & $6 / 16 / 4$ & 2.54 & 0.440 & $\times$ \\
\hline
\end{tabular}

These transparent surfaces have been simulated in the building thermal zones, in order to investigate their effect on the annual energy demands. Furthermore, to overcome the poor building insulation 
highlighted in Figure 6, the possibility of an external insulation based on a coating made of expanded polystyrene has been taken into account. This insulating material is characterized by a thermal conductivity equal to $0.040 \mathrm{~W} / \mathrm{mK}$, a specific heat capacity equal to $1.470 \mathrm{~kJ} / \mathrm{kgK}$ and a mass density equal to $25 \mathrm{~kg} / \mathrm{m}^{3}$. Several thicknesses of the external coating have been tested ranging from $2 \mathrm{~cm}$ to $10 \mathrm{~cm}$. As a further step, the horizontal surfaces have been insulated with an expanded polystyrene layer equal to $13 \mathrm{~cm}$, located between the cement mortar and the waterproof membrane. The new thermal transmittance values are listed in Table 7. A $10 \mathrm{~cm}$-thick vertical coating and a roof insulation with an expanded polystyrene layer characterized by a thickness equal to $13 \mathrm{~cm}$, ensure compliance with the thermal transmittance limits (climatic zone D), according to the Italian standard [30]. Table 8 lists the walls and roof dynamic thermal performance after retrofit.

Table 7. Thermal transmittance values after retrofit.

\begin{tabular}{ccc}
\hline Element & $\begin{array}{c}\text { Thermal Transmittance } \\
{\left[\mathbf{W} / \mathbf{m}^{2} \mathbf{K}\right]}\end{array}$ & $\begin{array}{c}\text { Thermal Transmittance Limit } \\
\text { (Climatic Zone D) }\end{array}$ \\
\hline Insulated Roof - EPS $13 \mathrm{~cm}$ & 0.253 & $\sqrt{ }$ \\
Wall - Coating $2 \mathrm{~cm}$ & 0.629 & $\times$ \\
Wall - Coating $4 \mathrm{~cm}$ & 0.478 & $\times$ \\
Wall - Coating $6 \mathrm{~cm}$ & 0.386 & $\times$ \\
Wall - Coating $8 \mathrm{~cm}$ & 0.324 & $\times$ \\
Wall - Coating $10 \mathrm{~cm}$ & 0.278 & $\sqrt{ }$ \\
\hline
\end{tabular}

Table 8. Walls and roof dynamic thermal performance after the refurbishment.

\begin{tabular}{|c|c|c|c|c|c|c|}
\hline & $\begin{array}{c}\text { Base Case } \\
\text { Walls } \\
\end{array}$ & $\begin{array}{l}\text { Wall-Coating } \\
2 \mathrm{~cm} \\
\end{array}$ & $\begin{array}{c}\text { Wall-Coating } \\
4 \mathrm{~cm} \\
\end{array}$ & $\begin{array}{c}\text { Wall-Coating } \\
6 \mathrm{~cm} \\
\end{array}$ & $\begin{array}{c}\text { Wall-Coating } \\
8 \mathrm{~cm} \\
\end{array}$ & $\begin{array}{c}\text { Wall-Coating } \\
10 \mathrm{~cm} \\
\end{array}$ \\
\hline Surface mass & $439 \mathrm{~kg} / \mathrm{m}^{2}$ & $439.5 \mathrm{~kg} / \mathrm{m}^{2}$ & $440 \mathrm{~kg} / \mathrm{m}^{2}$ & $440.5 \mathrm{~kg} / \mathrm{m}^{2}$ & $441 \mathrm{~kg} / \mathrm{m}^{2}$ & $441.5 \mathrm{~kg} / \mathrm{m}^{2}$ \\
\hline $\begin{array}{l}\text { Dynamic thermal } \\
\text { transmittance }\end{array}$ & $0.157 \mathrm{~W} / \mathrm{m}^{2} \mathrm{~K}$ & $0.044 \mathrm{~W} / \mathrm{m}^{2} \mathrm{~K}$ & $0.025 \mathrm{~W} / \mathrm{m}^{2} \mathrm{~K}$ & $0.018 \mathrm{~W} / \mathrm{m}^{2} \mathrm{~K}$ & $0.013 \mathrm{~W} / \mathrm{m}^{2} \mathrm{~K}$ & $0.011 \mathrm{~W} / \mathrm{m}^{2} \mathrm{~K}$ \\
\hline Thermal attenuation & 0.172 & 0.070 & 0.052 & 0.045 & 0.042 & 0.039 \\
\hline \multirow[t]{2}{*}{ Thermal lag } & $12.86 \mathrm{~h}$ & $14.41 \mathrm{~h}$ & $14.71 \mathrm{~h}$ & $14.9 \mathrm{~h}$ & $15.08 \mathrm{~h}$ & $15.28 \mathrm{~h}$ \\
\hline & Base Case Roof & $\begin{array}{c}\text { Roof-13 cm } \\
\text { EPS } \\
\end{array}$ & & & & \\
\hline Surface mass & $369.7 \mathrm{~kg} / \mathrm{m}^{2}$ & $372.9 \mathrm{~kg} / \mathrm{m}^{2}$ & & & & \\
\hline $\begin{array}{l}\text { Dynamic thermal } \\
\text { transmittance }\end{array}$ & $0.507 \mathrm{~W} / \mathrm{m}^{2} \mathrm{~K}$ & $0.022 \mathrm{~W} / \mathrm{m}^{2} \mathrm{~K}$ & & & & \\
\hline Thermal attenuation & 0.344 & 0.085 & & & & \\
\hline Thermal lag & $9.29 \mathrm{~h}$ & $12.69 \mathrm{~h}$ & & & & \\
\hline
\end{tabular}

\section{Results and Discussion}

\subsection{Retrofit Evaluation through Dynamic Simulations}

In order to appreciate the transparent surface influence on the annual energy demands, the elements listed in Table 6 have been tested. The results shown in Figure 9, concerning the whole building, allow highlighting the simultaneous effects of varying thermal transmittance and solar gain factor (g-value). By progressively increasing insulation from the "ante operam" (single glaze) configuration, it is possible 
to obtain heating demand reductions of $-40 \%$ (double glaze air) or $-47 \%$ (double glaze argon). On the other hand, the window solar gain factor plays a fundamental role during the summer: Figure 9 shows that the cooling demand reduction reaches a value equal to $-40 \%$ by using a solar control glaze. In this case, the solar control glaze, represented by the double pane 6/16/4 with air, allows almost halving the cooling energy demand and, at the same time, it is effective during the winter. Its thermal transmittance is higher than the one provided by the double glaze with argon (see Table 6) but, despite this, it allows reducing the heating energy demand $(-31 \%)$ compared with the ante operam situation.

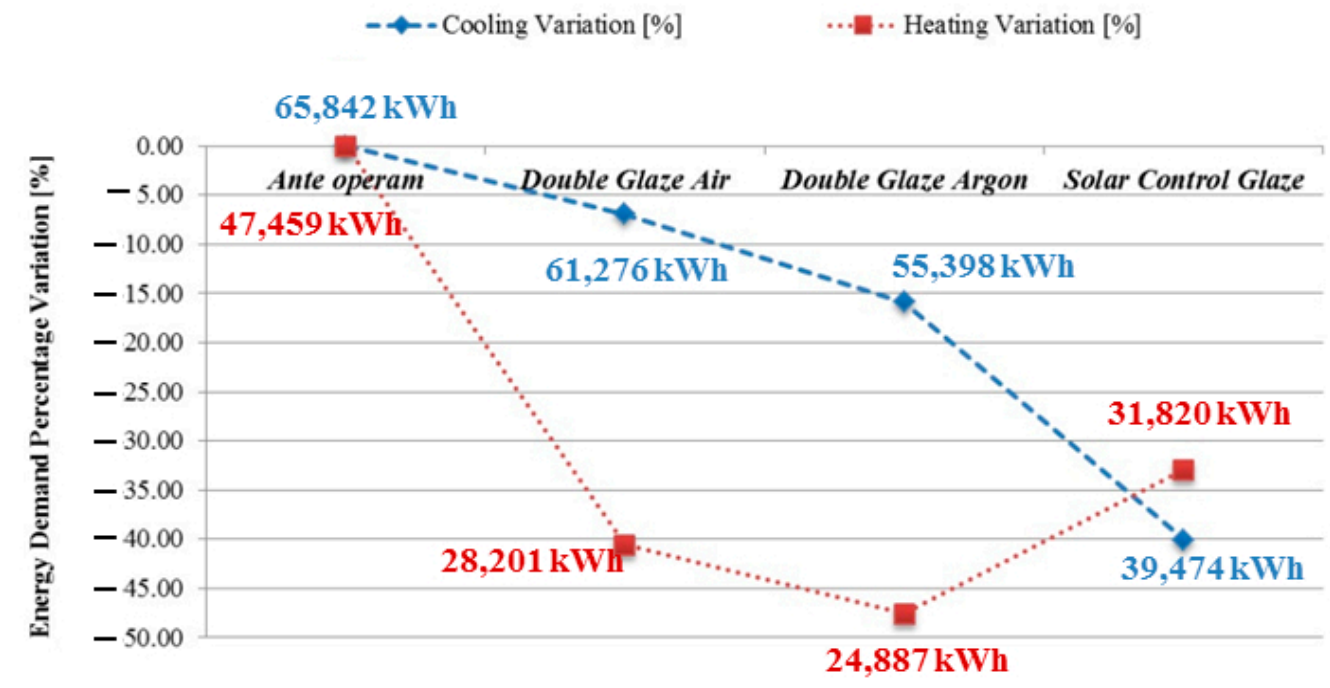

Figure 9. Energy needs percentage variations as a function of different transparent surfaces.

In order to investigate the opaque surfaces influence on the annual energy demands, the addition of an external insulation layer, consisting of an expanded polystyrene coating, has been simulated. A progressively increased thickness of the external coating, with a resulting reduction of the overall thermal transmittance, has been considered. It turns out that it is necessary to employ at least a $10 \mathrm{~cm}$-thick insulation layer to comply with the thermal transmittance limit imposed by the Italian Standards (thermal transmittance limits, for the climatic zone D, are $0.290 \mathrm{~W} / \mathrm{m}^{2} \mathrm{~K}$ for vertical opaque surfaces and $0.260 \mathrm{~W} / \mathrm{m}^{2} \mathrm{~K}$ for horizontal ones). Eight types of possible interventions, whose details are reported in Table 9, have been compared. The results are reported in Figure 10.

Table 9. Description of the interventions.

\begin{tabular}{cc}
\hline Name & Description \\
\hline Ante Operam & Base case \\
Int. 1 & Insulated Roof-EPS $13 \mathrm{~cm}$ \\
Int. 2 & Wall-Coating $2 \mathrm{~cm}$ \\
Int. 3 & Wall-Coating $4 \mathrm{~cm}$ \\
Int. 4 & Wall-Coating $6 \mathrm{~cm}$ \\
Int. 5 & Wall-Coating $8 \mathrm{~cm}$ \\
Int. 6 & Wall-Coating $10 \mathrm{~cm}$ \\
Int. 7 & Wall $($ Coating $10 \mathrm{~cm})+$ Roof $($ EPS $13 \mathrm{~cm})$ \\
Final Retrofit & Wall (Coating $10 \mathrm{~cm})+$ Roof $($ EPS $13 \mathrm{~cm})+$ Double glaze with air $($ low g) \\
\hline
\end{tabular}


Intervention 7 represents the best solution to mitigate the wintry heat dispersions with an energy demand reduction of about $78 \%$. At the same time the cooling energy demand increases of about $45 \%$. This happens because, during the summer nights, when the outer temperature decreases below the inner temperature, a higher insulation limits the heat transfer to the outside. For this reason, the Intervention 7 and the solar control glaze employment have been concurrently simulated to reduce also the cooling demand. Using a Double glaze with air (low g) allows obtaining a heating demand reduction equal to $-98 \%$ and a cooling energy increase limited to $1 \%$ (see Figure 9, Final Retrofit).

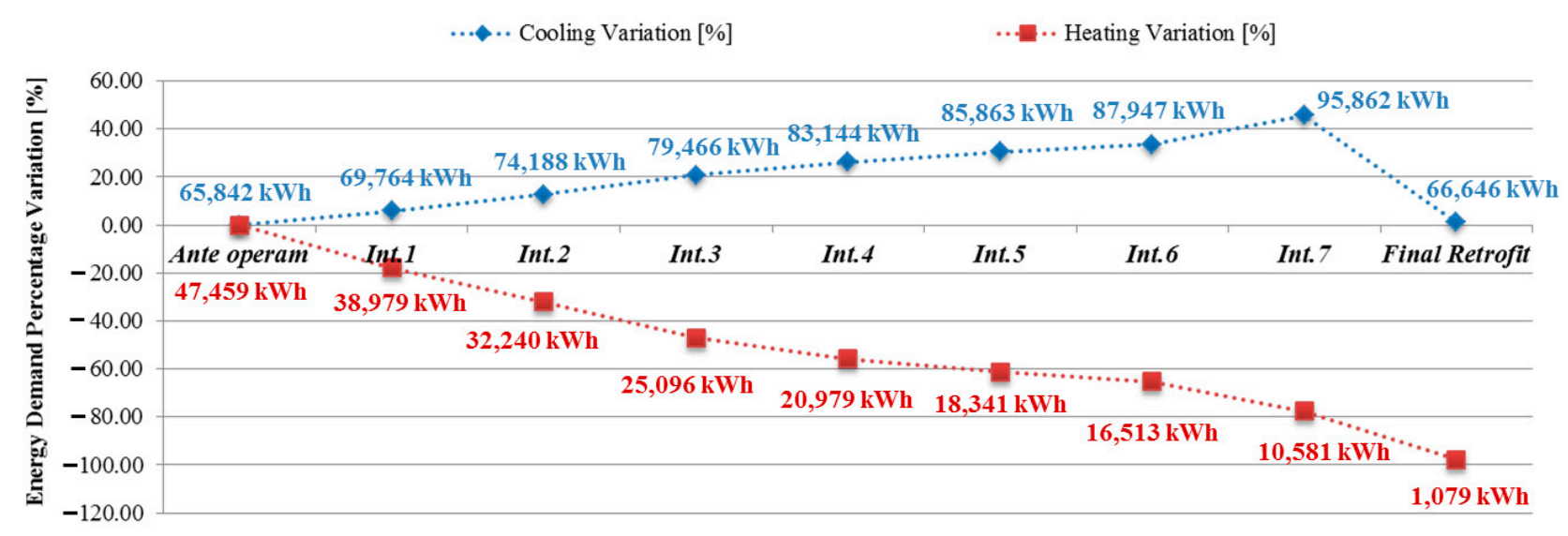

Figure 10. Effect of the opaque surface insulation.

It is worth stressing, in conclusion, that a higher envelope insulation does not represent the best way to optimize the building behavior during summer [31]. However, in the overall yearly energy balance, such retrofit measure can still prove beneficial if it is taken together with a proper way to limit the summer temperature increase arising from solar contribution, as obtainable with a low g-value glass.

\subsection{Payback Time}

In this case study, the material installation cost is approximately equal to $60 € / \mathrm{m}^{2}$ and the heating plant is more than 20 years old, so the system efficiency can be considered equal to 0.6. Moreover, the energy cost is equal to $0.0866 € / \mathrm{kWh}$ (taking into account natural gas) and the building is placed in Rome (climatic zone D) with 1415 degree days. Figure 11 shows the payback time values as a function of the Expanded Polystyrene (EPS) thickness.

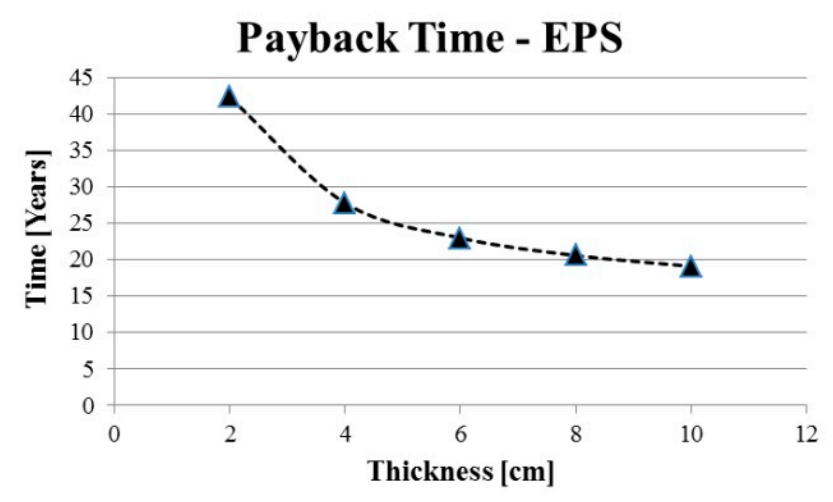

Figure 11. Payback times as a function of the EPS thickness. 
Equation (3) shows that the payback time is a function of the wall's thermal resistance before and after the retrofit, without considering materials properties. Taking into account different insulation materials, it is possible to calculate payback times dependent on the material unit costs. There are a lot of insulating solutions, such as glass fiber panels, rock fiber panels, wood fiber panels or natural cork fiber panels. Setting $R_{\text {ante }}$ equal to $1 \mathrm{~m}^{2} \mathrm{~K} / \mathrm{W}$ and $E$ equal to 0.6 , considering a material installation cost that ranges from $30 € / \mathrm{m}^{2}$ to $60 € / \mathrm{m}^{2}$, the payback time as a function of material thickness and of its installation cost has been calculated. The result is reported in Figure 12 and shows that the payback time can be reduced to less than 10 years with a proper combination of cost and thickness of the insulating material.

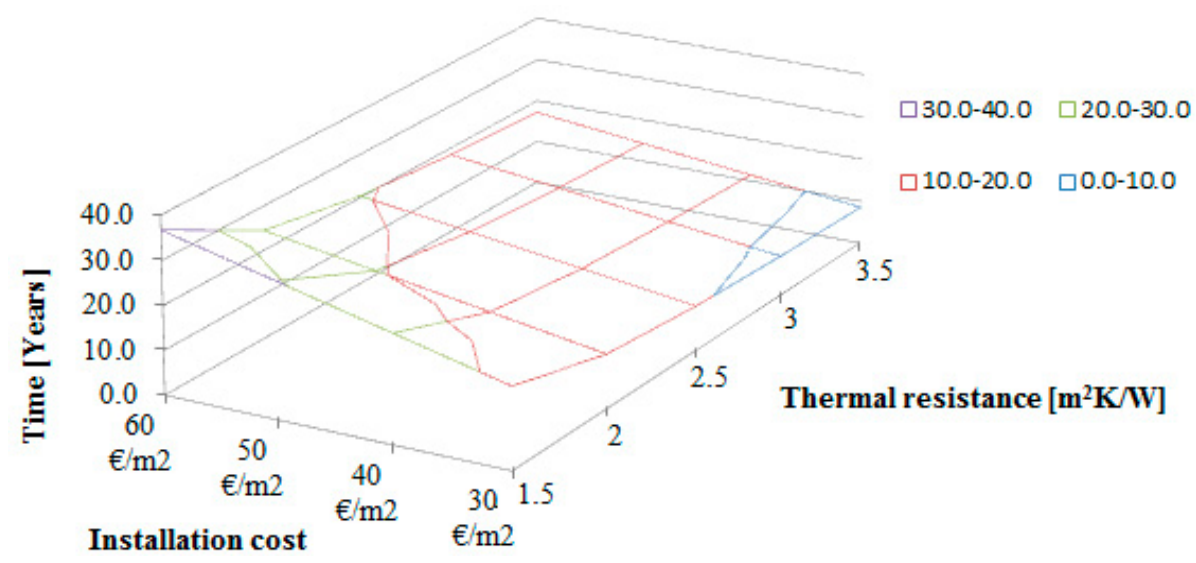

Figure 12. Payback time considering different installation costs and thermal resistances after retrofit.

\section{Conclusions}

In this paper, an early-50s building has been analyzed, conducting a measurement campaign to investigate the building's characteristics and its vulnerability. After that, some retrofit alternatives have been simulated and compared by means of a calibrated model.

Regarding transparent surfaces, three different windows have been tested. The results show that a higher thermal insulation allows obtaining the best heating demand reductions, but the window solar gain factor plays a fundamental role during summer. Indeed, a solar control glaze allows halving the cooling energy demand and, at the same time, it is effective during winter.

Concerning opaque surfaces, the effect of an external insulating coating of expanded polystyrene has been studied. The results show that a higher thermal insulation allows mitigating the wintry heat dispersions but, on the other hand, it involves a cooling energy demand increase, which can reach up to $45 \%$.

The simultaneous use of solar control glazes and external coating turns out to be the best solution. However, the installation of new windowed elements requires very high costs and, therefore, choosing this kind of intervention needs to be accurately evaluated as a function of the initial economic budget.

In deciding which building energy retrofit measure to take, it is important to determine how quickly the energy upgrading will be repaid. Payback times can range approximately between 10 and 35 years, as a function of installation costs and required performance. The PBT evaluation performed in this work took into account only the heating system, but, as already observed, a higher insulation involves a cooling 
energy demand increase. It would be therefore necessary to evaluate both elements and find a proper tradeoff between winter and summer energy demands.

\section{Author Contributions}

Luca Evangelisti and Claudia Guattari designed the research and performed the measurements. Luca Evangelisti made the simulations. All the authors analyzed and discussed the data and wrote the paper.

\section{Conflicts of Interest}

The authors declare no conflict of interest.

\section{References}

1. Salata, F.; de Lieto Vollaro, A.; Ferraro, A. An economic perspective on the reliability of lighting systems in building with highly efficient energy: A case study. Energy Convers. Manag. 2014, 84, 623-632.

2. Salata, F.; de Lieto Vollaro, A.; de Lieto Vollaro, R. A case study of technical and economic comparison among energy production systems in a complex of historic buildings in Rome. Energy Procedia 2014, 45, 482-491.

3. Salata, F.; de Lieto Vollaro, A.; de Lieto Vollaro, R.; Mancieri, L. Method for energy optimization with reliability analysis of a trigeneration and teleheating system on urban scale: A case study. Energy Build. 2015, 86, 118-136.

4. Ascione, F.; Bianco, N.; de Masi, R.F.; de'Rossi, F.; Vanoli, G.P. Energy retrofit of an educational building in the ancient center of Benevento. Feasibility study of energy savings and respect of the historical value. Energy Build. 2015, 95, 172-183.

5. Pisello, A.L.; Rossi, F.; Cotana, F. Summer and winter effect of innovative cool roof tiles on the dynamic thermal behavior of buildings. Energies 2014, 7, 2343-2361.

6. Friedman, C.; Becker, N.; Erell, E. Energy retrofit of residential building envelopes in Israel: A cost benefit analysis. Energy 2014, 77, 183-193.

7. Evangelisti, L.; Battista, G.; Guattari, C.; Basilicata, C.; de Lieto Vollaro, R. Influence of the thermal inertia in the European simplified procedures for the assessment of buildings' energy performance. Sustainability 2014, 6, 4514-4524.

8. Foucquier, A.; Robert, S.; Suard, F.; Stéphan, L.; Jay, A. State of the art in building modelling and energy performances prediction: A review. Renew. Sustain. Energy Rev. 2013, 23, 272-288.

9. Fumo, N. A review on the basics of building energy estimation. Renew. Sustain. Energy Rev. 2014, 31, 53-60.

10. Baldinelli, G.; Asdrubali, F.; Baldassarri, C.; Bianchi, F.; D’Alessandro, F.; Schiavoni, S.; Basilicata, C. Energy and environmental performance optimization of a wooden window: A holistic approach. Energy Build. 2014, 79, 114-131.

11. Baldinelli, G.; Bianchi, F. Windows thermal resistance: Infrared thermography aided comparative analysis among finite volumes simulations and experimental methods. Appl. Energy 2014, 136, 250-258. 
12. Asdrubali, F.; D’Alessandro, F.; Schiavoni, S. A review of unconventional sustainable building insulation materials. Sustain. Mater. Technol. 2015, 4, 1-17.

13. Peruzzi, L.; Salata, F.; de Lieto Vollaro, A.; de Lieto Vollaro, R. The reliability of technological systems with high energy efficiency in residential buildings. Energy Build. 2014, 68, 19-24.

14. ISO. Thermal Insulation-Building Elements-In-Situ Measurement of Thermal Resistance and Thermal Transmittance; ISO 9869-1; ISO: Geneva, Switzerland, 2014.

15. Asdrubali, F.; D’Alessandro, F.; Baldinelli, G.; Bianchi, F. Evaluating in situ thermal transmittance of green buildings masonries-A case study. Case Stud. Constr. Mater. 2014, 1, 53-59.

16. De Lieto Vollaro, R.; Guattari, C.; Evangelisti, L.; Battista, G.; Carnielo, E.; Gori, P. Building energy performance analysis: A case study. Energy Build. 2015, 87, 87-94.

17. Asdrubali, F.; Baldinelli, G.; Bianchi, F.; Sambuco, S. A comparison between environmental sustainability rating systems LEED and ITACA for residential buildings. Build. Environ. 2015, 86, 98-108.

18. Evangelisti, L.; Battista, G.; Guattari, C.; Basilicata, C.; de Lieto Vollaro, R. Analysis of two models for evaluating energy performance of different buildings. Sustainability 2014, 6, 5311-5321.

19. De Lieto Vollaro, R.; Evangelisti, L.; Carnielo, E.; Battista, G.; Gori, P.; Guattari, C.; Fanchiotti, A. An Integrated Approach for an Historical Buildings Energy Analysis in a Smart Cities Perspective. Energy Procedia 2014, 45, 372-378.

20. TRNSYS. A Transient Systems Simulation Program. Available online: http://sel.me.wisc.edu/ trnsys (accessed on 7 January 2015).

21. Mitalas, G.P. Transfer function method of calculating cooling loads, heat extraction and space temperature. ASHRAE J. 1973, 14, 54-56.

22. De Lieto Vollaro, R.; Evangelisti, L.; Battista, G.; Gori, P.; Guattari, C.; Fanchiotti, A. Bus for urban public transport: Energy performance optimization. Energy Procedia 2014, 48, 731-738.

23. De Lieto Vollaro, R.; Calvesi, M.; Battista, G.; Evangelisti, L.; Botta, F. Calculation model for optimization design of the low impact energy systems for the buildings. Energy Procedia 2014, 48, 1459-1467.

24. Battista, G.; Evangelisti, L.; Guattari, C.; Basilicata, C.; de Lieto Vollaro, R. Buildings energy efficiency: Interventions analysis under a smart cities approach. Sustainability 2014, 6, 4694-4705.

25. Lam, K.P.; Zhao1, J.; Ydstie, E.B.; Wirick, J.; Qi, M.; Park, J. An energy plus whole building energy model calibration method for office buildings using occupant behavior data mining and empirical data. In Proceedings of the 2014 ASHRAE/IBPSA-USA Building Simulation Conference, Atlanta, GA, USA, 10-12 September 2014.

26. American Society of Heating, Refrigerating and Air Conditioning Engineers. Guideline 14-2002: Measurement of Energy and Demand Savings; ASHRAE: Atlanta, GA, USA, 2002.

27. Moncef, K. Weatherization and Energy Efficiency Improvement for Existing Homes: An Engineering Approach; CRC Press: Boca Raton, FL, USA, 2012; pp. 133-134.

28. TESTO 435-2 - Strumento multifunzione. Available online: http://www.testo.it/dettagli_prodotto/ $0563+4352 /$ testo-435-2-Strumento-multifunzione (accessed on 7 January 15).

29. UNI TS 11300-1, Determination of the Buildings Energy Demand for the Air-Conditioning in Summer and Winter; Available online: www.uni.com (assessed on 28 July 2015). (In Italian) 
30. Ministry of Economic Development. Available online: http://www.sviluppoeconomico.gov.it/ (assessed on 28 July 2015). (In Italian)

31. Masoso, O.T.; Grobler, L.J. A new and innovative look at anti-insulation behaviour in building energy consumption. Energy Build. 2008, 40, 1889-1894.

(C) 2015 by the authors; licensee MDPI, Basel, Switzerland. This article is an open access article distributed under the terms and conditions of the Creative Commons Attribution license (http://creativecommons.org/licenses/by/4.0/). 